\title{
Experimental Study on Mechanical Properties of Q690 High-Strength Steel after High Cycle Fatigue Damage
}

\author{
Ran Luo \\ School of Civil Engineering and Architecture, Southwest University of Science and Technology, Mianyang, China \\ Email:11406947313@126.com
}

How to cite this paper: Luo, R. (2022) Experimental Study on Mechanical Properties of Q690 High-Strength Steel after High Cycle Fatigue Damage. Open Journal of Applied Sciences, 12, 243-255.

https://doi.org/10.4236/ojapps.2022.122018

Received: January 27, 2022

Accepted: February 20, 2022

Published: February 23, 2022

Copyright $\odot 2022$ by author(s) and Scientific Research Publishing Inc. This work is licensed under the Creative Commons Attribution International License (CC BY 4.0).

http://creativecommons.org/licenses/by/4.0/

\begin{abstract}
Through the static tensile test of Q690 high-strength steel, the relevant mechanical parameters are obtained and the maximum fatigue load is determined. The fatigue life is measured by the fatigue test under the load. According to the fatigue cumulative damage method, the number of fatigue pre-damage vibration is designed in proportion. Then the fatigue pre-damage test is carried out on the high-strength steel, the stress-strain curve and the variation of residual mechanical property reduction coefficient with fatigue damage were drawn. The results show that: compared with the undamaged specimens, the yield strength and tensile strength of Q690 steel are less affected by fatigue damage, but the elongation changes more significantly, and the elastic modulus is not significantly affected. Finally, through the change of mechanical properties of Q690 high-strength steel with different fatigue damage, it provides a scientific basis for the performance evaluation of existing Q690 high-strength steel structure after fatigue damage.
\end{abstract}

\section{Keywords}

Q690 High-Strength Steel, Fatigue Damage, Mechanical Property, Stress-Strain Curve, Reduction Factor

\section{Introduction}

High-strength steel refers to structural steel with a yield strength of $\geq 460 \mathrm{MPa}$. Compared with ordinary steel, high-strength steel has great differences in material properties and chemical composition [1]. High-strength structural steel has the advantages of high rigidity, good plasticity and toughness. The use of high-strength steel can not only reduce the section size of components and re- 
duce the overall steel consumption of the building, but also effectively reduce the self-weight of the structure and reduce the project cost, so as to obtain good economic benefits; from the seismic point of view, the overall stability coefficient of high-strength steel is relatively high, and the use of high-strength steel can improve the seismic performance of the structure [2] [3]. At present, high-strength steel is used extremely frequently in the construction industry, automobile production, bridge construction, transmission tower structures, etc. These components will be subjected to continuous random alternating loads such as wind load, wave load, vehicle load, crane load and crowd load for a long time during the service period, and fatigue is the process of local damage to the structure under the load, and the cumulative damage will cause Cracks to occur in components, and fatigue failure occurs when the actual stress on the structure is greater than its own resistance [4]. According to statistics, in various structural failure cases, fatigue damage accounts for $50 \%$ to $90 \%$ [5], causing huge economic losses and casualties to society.

Up to now, scholars have carried out a series of tests on the mechanical properties of steel after fatigue damage. Zhang et al. [6] studied the mechanical properties of Q690 high-strength steel after low-cycle fatigue damage, and found that fatigue damage has a great influence on the ultimate strength, yield strength and elongation rate of high-strength steel, all of which are negatively correlated with fatigue damage, but elastic modulus Quantity is less affected. Tan et al. [7] conducted a study on the mechanical properties of A7005 aluminum alloy materials after fatigue cycles, and found that after 0, 104, 105, 106, and 107 cycles, the residual yield strength and ultimate strength of the material continued to increase before 105 cycles, and reached the maximum value, and then gradually decreased with the increase of the number of fatigue cycles. Wang et al. [8] conducted fatigue pre-damage test on $\mathrm{P} 92$ steel and quantitatively described its residual mechanical properties. It was found that the yield strength, tensile strength and elongation of P92 steel were negatively correlated with fatigue damage, which decreased with the increase of load grade. Wu [9] conducted tensile tests on normalized 45 steel bar fatigue specimens damaged by different fatigue cycles to observe the changes in residual mechanical properties, and found that when the number of cycles is small, the conditional proportional limit increases with the number of cycles. While increasing, the area shrinkage rate gradually decreases, and the tensile strength is not sensitive to the number of cycles and is basically unaffected. However, in the later stage of the fatigue process, these three values suddenly decrease due to the generation of micro-cracks.

Therefore, in order to explore the effect of alternating loads on high-strength steel structures, it is necessary to study the mechanical properties of high-strength steels after fatigue damage. However, at present, domestic scholars have more comprehensive research on the mechanical properties of steel after corrosion [4], high temperature [10], and the fatigue properties of steel [11], there are still few studies on the residual mechanical properties of steel after fatigue damage, and relevant data are still lacking. However, in practical engineering, the engineering 
structure is often damaged due to fatigue damage. Therefore, in this paper, the static tensile test of Q690 steel after different degrees of fatigue pre-damage is carried out, the mechanical property parameters are obtained, and the stress-strain curve is given. Analyze the impact of fatigue damage on various mechanical properties, so as to provide a scientific basis for the evaluation of mechanical properties of high-strength steel structure after fatigue damage, and obtain the fatigue damage by detecting the vibration times of steel structure. Based on the mathematical model established in this paper, the mechanical parameters of the Q690 high-strength steel after fatigue damage are obtained and compared with the bearing capacity of the reinforced structure, which provides technical support for the maintenance and reinforcement of the Q690 high-strength steel structure.

\section{Experimental Program}

\subsection{Specimen Size}

In this test, Q690 high-strength steel was selected. According to the regulations in the literature [12], the tensile specimen and the fatigue specimen were processed by wire cutting. The geometry and specific dimensions are shown in Figure 1.

\subsection{Test Equipment}

This test was carried out in the Sichuan Key Laboratory of "Engineering Materials and Structural Shock and Vibration", Southwest University of Science and

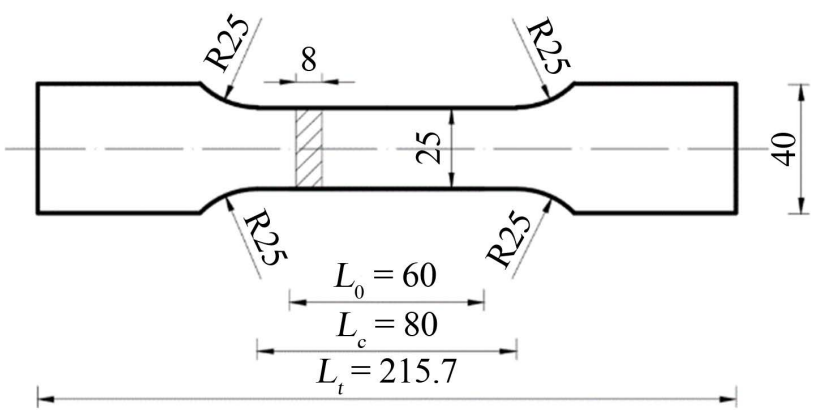

(a)

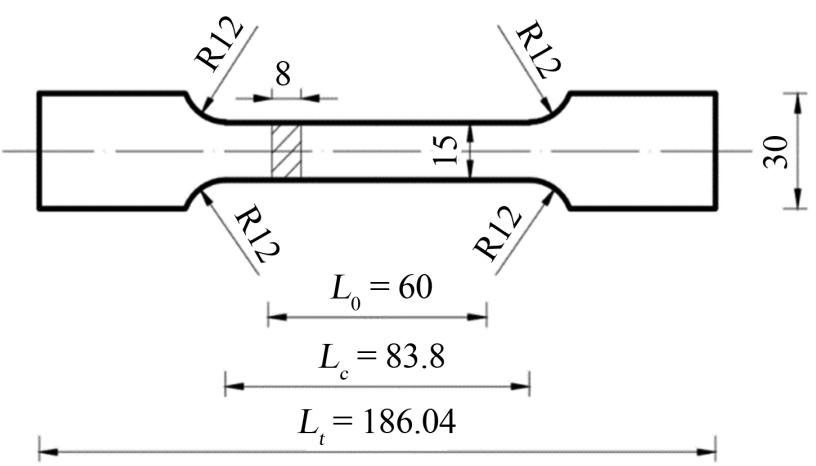

(b)

Figure 1. Dimension of specimen (size: $\mathrm{mm}$ ). (a) Tensile test piece; (b) Fatigue specimen. 
Technology. First, in accordance with the specification GB/T 228.1-2010 "Tensile Test of Metal Materials Part 1: Test Method at Room Temperature” [13], a universal testing machine was used to conduct a tensile test on the specimen. The universal testing machine is mainly composed of the main engine, a hydraulic power source, and a testing system. The maximum testing force of the testing machine is $300 \mathrm{kN}$, as shown in Figure 2(a). Then, according to the relevant provisions of GB/T 3075-2008 “Axial Force Control Method for Fatigue Test of Metal Materials" [12], the axial fatigue test of the specimen is carried out. The selected equipment is RG-9025 electro-hydraulic servo fatigue testing machine. The frequency range is $0.01-100 \mathrm{~Hz}$, the maximum load is $\pm 250 \mathrm{kN}$, and the measurement accuracy is less than $1.0 \%$. The fatigue testing machine is shown in Figure 2(b).

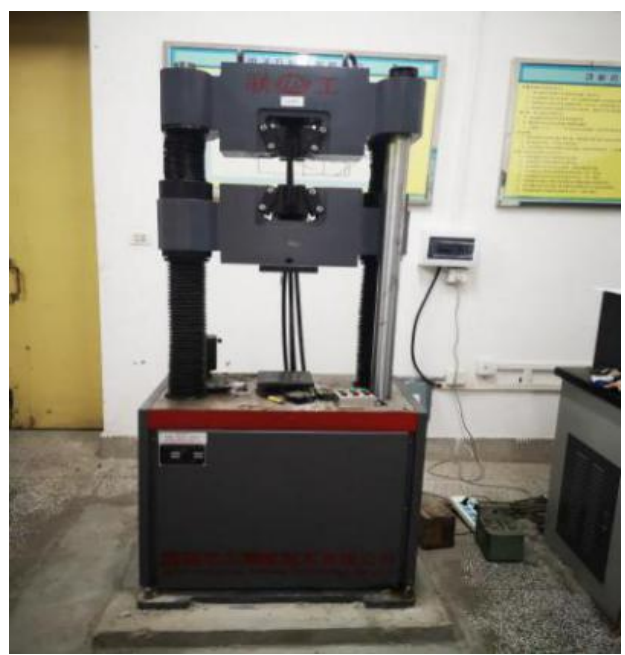

(a)

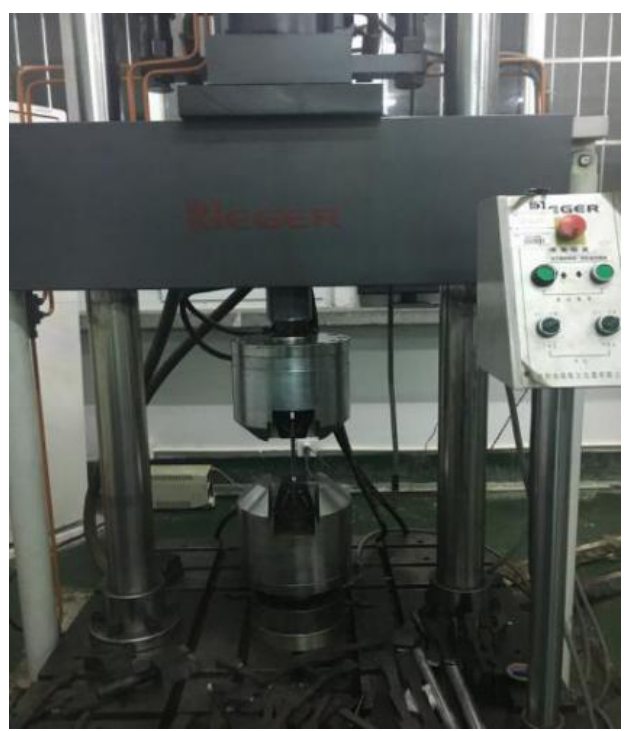

(b)

Figure 2. Experimental device. (a) Electro-hydraulic servo universal testing machine; (b) Fatigue testing machine. 


\subsection{Test Method}

This test consists of three parts: fatigue test, fatigue pre-damage test and static tensile test. Three groups of Q690 tensile specimens were first stretched to obtain their related mechanical property parameters, as shown in Table 1. Among them, $f_{\mathrm{y}}$ is the yield strength, it refers to the stress strength corresponding to the yield phenomenon of metal materials. $f_{\mathrm{u}}$ is the ultimate strength, after entering the strengthening stage, the steel will have unrecoverable plastic deformation, and with the increase of tension, there will be obvious necking phenomenon, and the final specimen will fracture. At this time, the corresponding stress is the ultimate strength, which is the maximum stress that the steel can bear before fracture. $E$ is the elastic modulus, it represents the ability of metal materials to resist elastic deformation. and $\delta$ is the elongation, it refers to the ratio of the extension length of the original gauge distance to the original gauge distance after tensile fracture of steel.

According to the literature [14] [15], the high-cycle fatigue load level is determined by the mean value of ultimate tensile strength. The maximum fatigue load $S_{\max }$ in this test is $0.66 f_{\mathrm{u}}$, that is, $584.6 \mathrm{MPa}$. According to the relevant regulations of the literature [12], the fatigue life $N$ of six Q690 high-strength steel specimens was tested under the axial tension-tension vibration with a stress level of 584.6 MPa. The specific values are shown in Table 2. The fatigue pre-damage value $D$ is determined by the ratio of the number of vibrations $\mathrm{n}$ required for fatigue pre-damage to the fatigue life $N$. Using the fatigue cumulative damage calculation method, it is determined that $D$ is $0.13,0.26$ and 0.39 respectively (that is, $\mathrm{n}$ is 15,000 times, 30,000 times and 45,000 times respectively), and then conduct pre-damage tests on 3 groups of Q690 high-strength steel specimens. Each group of tests is set with 3 specimens, that is, they vibrate for a set number of times and then stop. The static tensile test was carried out on the above 9 fatigue pre-damage specimens, and a series of mechanical property parameters and stress-strain relationship curves were obtained. Through the comparative analysis with the results of non-damaged specimens, the variation law of relevant

Table 1. Mechanical property parameters of Q690 high-strength steel.

\begin{tabular}{ccccc}
\hline group & $f_{\mathrm{y}} / \mathrm{MPa}$ & $f_{\mathrm{u}} / \mathrm{MPa}$ & $E / \mathrm{GPa}$ & $\delta / \%$ \\
\hline 1 & 798.28 & 886.00 & 208.70 & 22.00 \\
2 & 792.54 & 885.42 & 206.41 & 23.00 \\
3 & 796.67 & 886.00 & 204.85 & 23.00 \\
mean & 795.83 & 885.81 & 206.65 & 22.67 \\
\hline
\end{tabular}

Table 2. Fatigue life of Q690 steel.

\begin{tabular}{cccccccc}
\hline$S_{\text {max }} / \mathrm{MPa}$ & $N_{1}$ & $N_{2}$ & $N_{3}$ & $N_{4}$ & $N_{5}$ & $N_{6}$ & mean \\
\hline 584.6 & 117,536 & 93,216 & 122,481 & 131,844 & 103,578 & 118,532 & 114,531 \\
\hline
\end{tabular}


mechanical property parameters of Q690 high-strength steel with fatigue damage was summarized.

\section{Test Results and Analysis}

\subsection{Stress-Strain Curve}

Based on the above test methods, static tensile tests were carried out on the three groups of damaged specimens to obtain stress-strain curves, as shown in Figure 3. It can be seen from the figure that the Q690 high-strength steel specimens have no obvious yield plateau after fatigue damage, so the yield strength value is taken as the stress value corresponding to $0.2 \%$ residual deformation; The increase of fatigue times makes the fatigue damage aggravate, and the ultimate strength of the specimens gradually decreases, and the strain difference in the strengthening stage increases with the increase of the number of vibrations, and reaches the maximum value at 45,000 times; the strain of the Q690 high-strength steel after fatigue damage has been reduced to varying degrees.

\subsection{Mechanical Properties Parameters}

Three groups of Q690 high-strength steel specimens with different damage degrees were subjected to static tensile tests to obtain the yield strength, ultimate strength, elastic modulus and elongation, and the average value of the mechanical parameters of each group of specimens, as shown in Table 3 shown.

\subsection{Mechanical Properties Analysis}

Table 4 shows the mean value and reduction coefficient of the mechanical property parameters of Q690 high-strength steel after different fatigue damage,

Table 3. Mechanical properties of Q690 high-strength steel with different vibration times.

\begin{tabular}{cccccc}
\hline working condition & Specimen & $f_{\mathrm{y}} / \mathrm{MPa}$ & $f_{\mathrm{u}} / \mathrm{MPa}$ & $E / \mathrm{GPa}$ & $\delta / \%$ \\
\hline \multirow{3}{*}{15,000 times } & $S_{1}-1$ & 760.78 & 863.83 & 209.03 & 22.00 \\
& $S_{1}-2$ & 769.03 & 868.58 & 209.60 & 21.50 \\
& $\mathrm{~S}_{1}-3$ & 784.20 & 864.67 & 210.00 & 21.50 \\
& mean & 771.34 & 865.69 & 209.54 & 21.67 \\
\hline \multirow{5}{*}{30,000 times } & $S_{2}-1$ & 760.00 & 873.17 & 207.40 & 19.00 \\
& $S_{2}-2$ & 727.37 & 832.92 & 203.30 & 20.70 \\
& $S_{2}-3$ & 760.83 & 835.14 & 204.30 & 19.10 \\
& mean & 749.40 & 847.08 & 205.00 & 19.58 \\
\hline \multirow{5}{*}{45,000 times } & $S_{3}-1$ & 724.62 & 815.21 & 204.20 & 15.50 \\
& $S_{3}-2$ & 724.79 & 807.92 & 204.80 & 17.50 \\
& $S_{3}-3$ & 733.71 & 805.81 & 203.50 & 13.00 \\
& mean & 727.71 & 809.65 & 204.17 & 15.33 \\
\hline
\end{tabular}




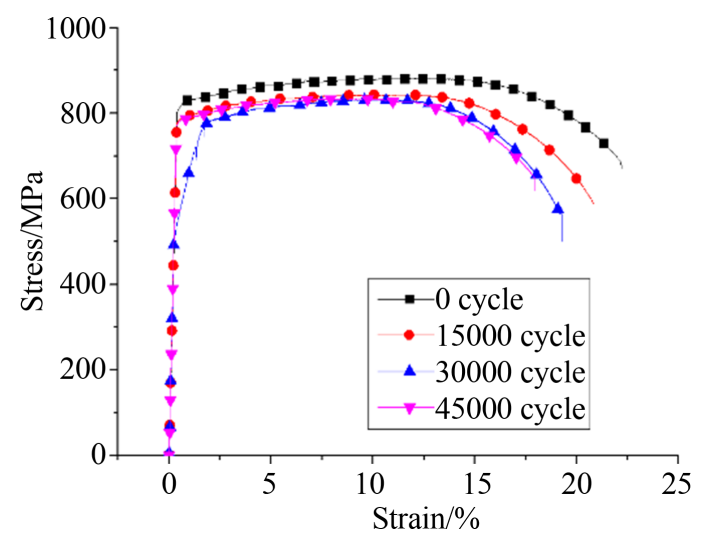

Figure 3. Stress-strain curves of Q690 high-strength steel.

Table 4. Reduction coefficient of mechanical properties parameters of Q690 high-strength steel with different fatigue damage.

\begin{tabular}{ccccccccc}
\hline $\mathrm{D}$ & $f_{\mathrm{y}, \mathrm{D}} / \mathrm{MPa}$ & $f_{\mathrm{y}, \mathrm{D}} / f_{\mathrm{y}}$ & $f_{\mathrm{u}, \mathrm{D}} / \mathrm{MPa}$ & $f_{u, \mathrm{D}} / f_{\mathrm{u}}$ & $E_{0} / \mathrm{GPa}$ & $E_{\mathrm{D}} / E$ & $\delta_{\mathrm{D}} / \%$ & $\delta_{\mathrm{D}} / \delta$ \\
\hline 0 & 795.83 & 1 & 885.81 & 1 & 206.65 & 1 & 22.67 & 1 \\
0.13 & 771.34 & 0.969 & 865.69 & 0.977 & 209.54 & 1.014 & 21.67 & 0.956 \\
0.26 & 749.4 & 0.942 & 847.08 & 0.956 & 205.00 & 0.992 & 19.58 & 0.864 \\
0.39 & 727.71 & 0.914 & 809.65 & 0.914 & 204.17 & 0.987 & 15.33 & 0.676 \\
\hline
\end{tabular}

and the reduction coefficient is the ratio of the mechanical parameter values after fatigue damage to the parameter values without damage. It can be seen from Table 4 that, except for the elastic modulus, which slightly increases when the fatigue damage value is small, the other mechanical property parameters gradually decrease with the increase of fatigue damage, and the greater the fatigue damage, the greater the difference; among which the change of elongation is the most obvious, while the elastic modulus is less affected.

\subsubsection{Yield Strength}

The variation law of the yield strength of Q690 high-strength steel after different fatigue vibration times is shown in Figure 4. Compared with the yield strength of undamaged steel, the yield strength of $S_{1}, S_{2}$ and $S_{3}$ specimens is reduced by $3.08 \%, 5.83 \%$ and $8.56 \%$ respectively. It can be seen that the yield strength of the specimens decreased after different fatigue damages, and with the increase of fatigue damage, the yield strength of the specimens showed a decreasing trend, but the decrease was not significant. The reason is that the fatigue damage causes different degrees of micro-cracks inside the steel. When the steel is subjected to tensile stress, the micro-cracks continue to develop. When the micro-cracks develop to be completely unstressed, the uncracked steel around the micro-cracks is borne. The stress and yield strength gradually decrease; The existence of internal micro-cracks reduces the plasticity of the steel so that there is no obvious yield plateau in the stress-strain curve. 


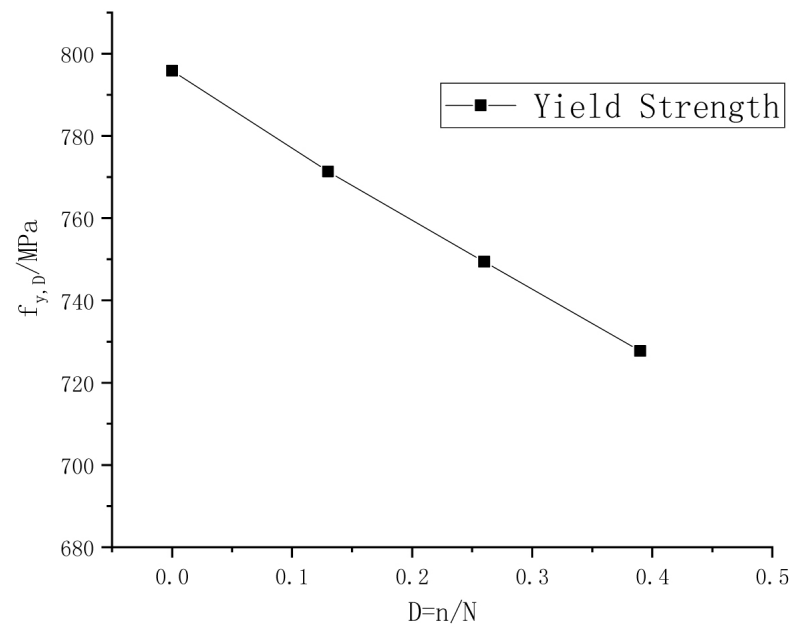

(a)

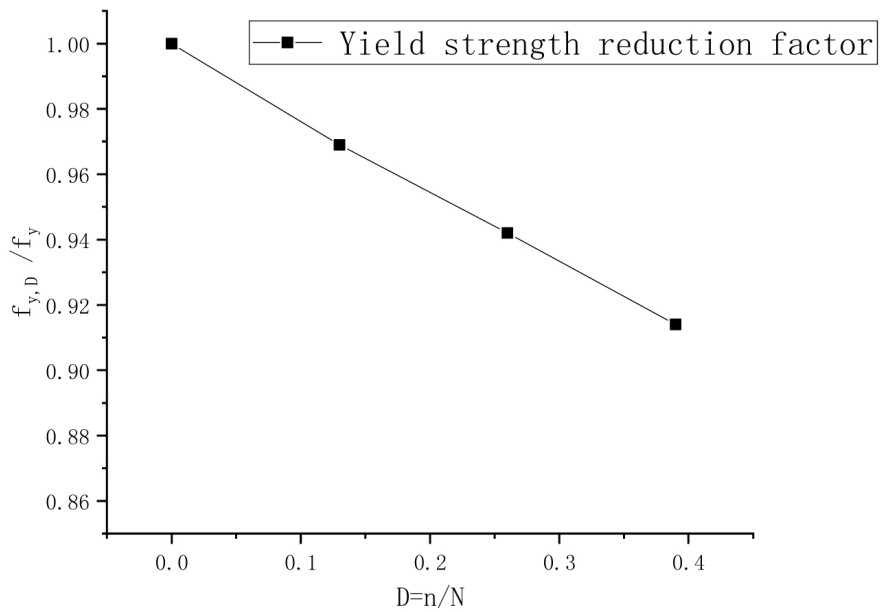

(b)

Figure 4. Yield strength comparison of Q690 high-strength steel. (a) Yield strength of Q690 high-strength steel; (b) Yield strength reduction factor of Q690 high-strength steel.

\subsubsection{Ultimate Strength}

As shown in Figure 5, the change law of ultimate strength of Q690 steel after different fatigue damage is obtained. Compared with the undamaged steel, the ultimate strength of the $S_{1}, S_{2}$ and $S_{3}$ specimens decreased by $2.27 \%, 4.37 \%$ and $8.60 \%$ respectively. It can be seen that the change law is basically similar to the above yield strength change law, and the ultimate strength of the specimen gradually decreases with the increase of fatigue damage, and the reduction range is not significant. The reason for this is the same as the reason for the decrease in yield strength mentioned above, which is affected by internal micro-cracks.

\subsubsection{Modulus of Elasticity}

After the specimen is subjected to different fatigue damage, the elastic modulus of $S_{1}$ specimen is only increased by $1.40 \%$ compared with the elastic modulus of undamaged steel under static tension, while the elastic moduli of the $S_{2}$ and $S_{3}$ specimens decreased by $0.80 \%$ and $0.90 \%$ respectively. The elastic modulus of 


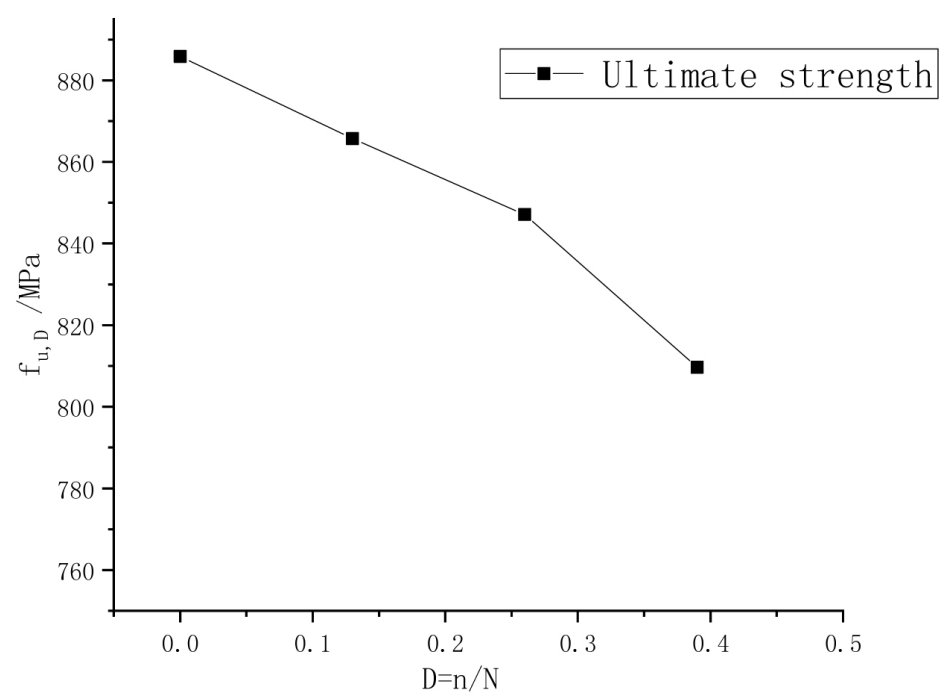

(a)

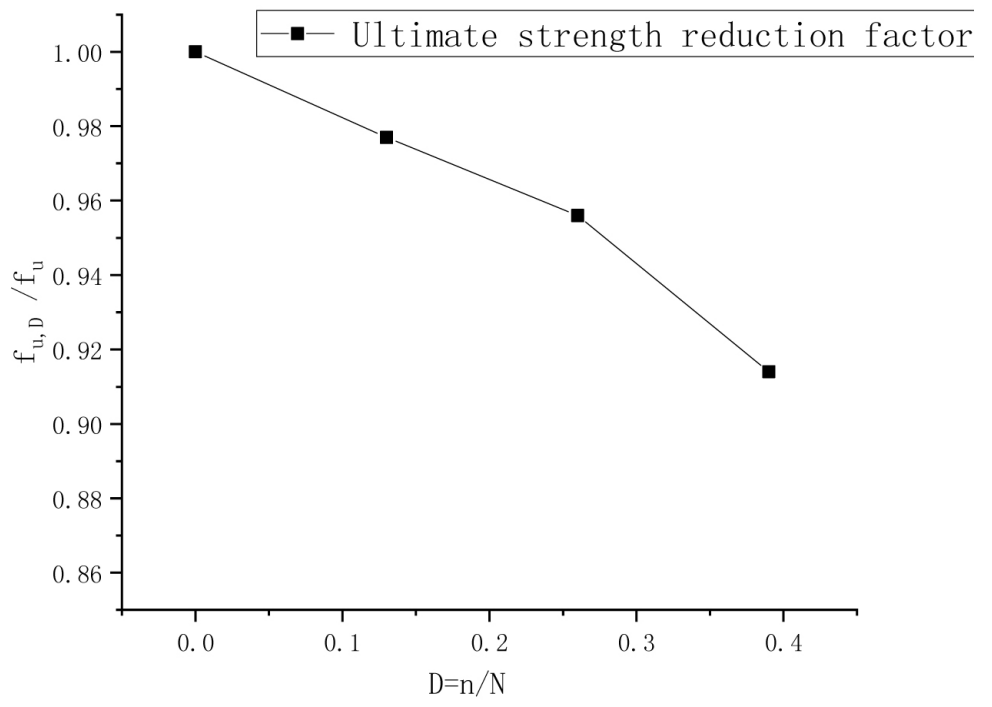

(b)

Figure 5. Ultimate strength comparison of Q690 high-strength steel. (a) Ultimate strength of Q690 high-strength steel (b) Ultimate strength reduction factor of Q690 high-strength steel.

Q690 steel is less affected by fatigue damage, the change is extremely insignificant, and there is no obvious rule (Figure 6).

\subsubsection{Elongation}

The change of elongation of the specimen is shown in Figure 7. Due to the influence of fatigue cycle softening, the elongation of Q690 high-strength steel gradually decreases [16]. Compared with the elongation of non-damaged steel in static stretching, the elongation of $S_{1}, S_{2}$ and $S_{3}$ specimens was $4.41 \%, 13.63 \%$ and $32.38 \%$ lower than that of non-damaged steel, respectively. It can be seen that the elongation of Q690 steel decreases with the increase of fatigue damage, and the greater the fatigue damage value, the more obvious the decreasing trend. 


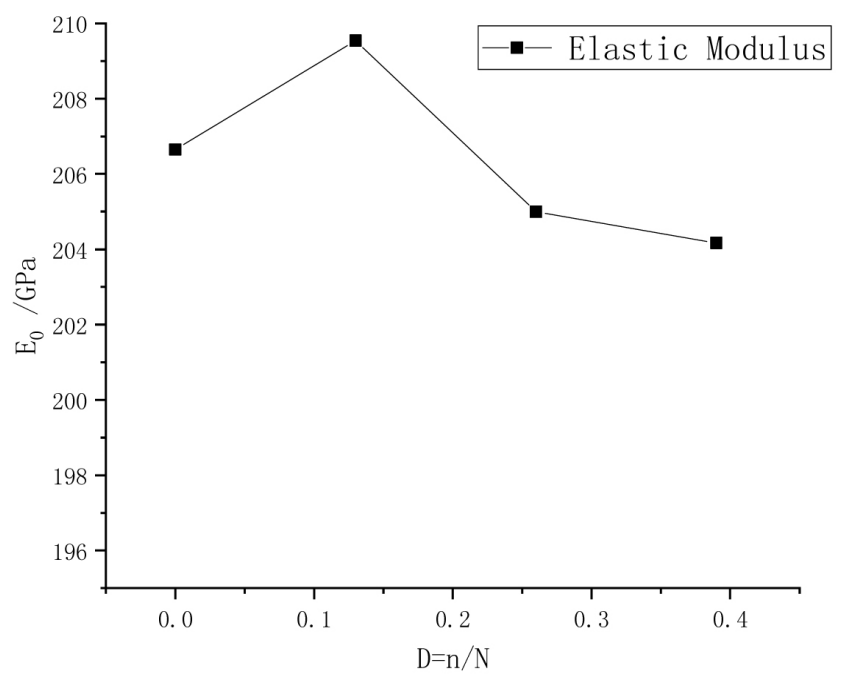

(a)

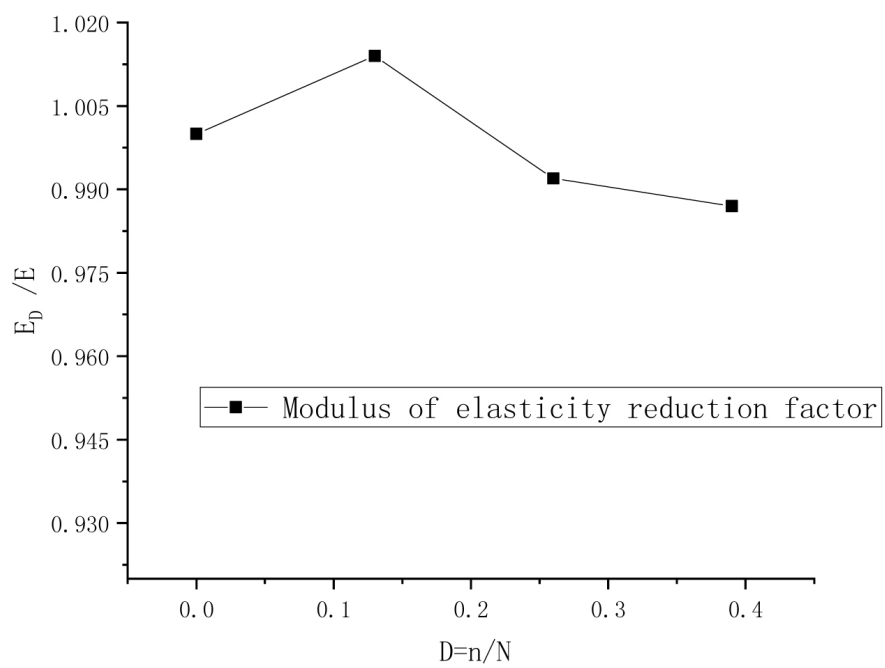

(b)

Figure 6. Comparison of elastic modulus of Q690 high-strength steel. (a) Elastic Modulus of Q690 high-strength steel (b) Elastic Modulus reduction factor of Q690 high-strength steel.

\subsubsection{Mathematical Model Analysis}

In the mechanical property analysis in the previous section, it can be clearly observed from the figure that the yield strength, ultimate strength and elongation of $S_{1}, S_{2}$ and $S_{3}$ specimens change linearly with the increase of fatigue damage, because fatigue damage will change the arrangement between grains in the metal, thus reducing various mechanical properties. Therefore, according to its changing trend, using the least squares method, the mathematical expressions of the yield strength, ultimate strength, elastic modulus and elongation reduction coefficient of Q690 high-strength steel after fatigue damage are obtained respectively with fatigue damage, such as Formulas (1), (2), (3) and (4) $(0 \leq D \leq 0.39)$, and the comparison between the experimental value of the reduction coefficient and the mathematical model, as shown in Figure 8. 


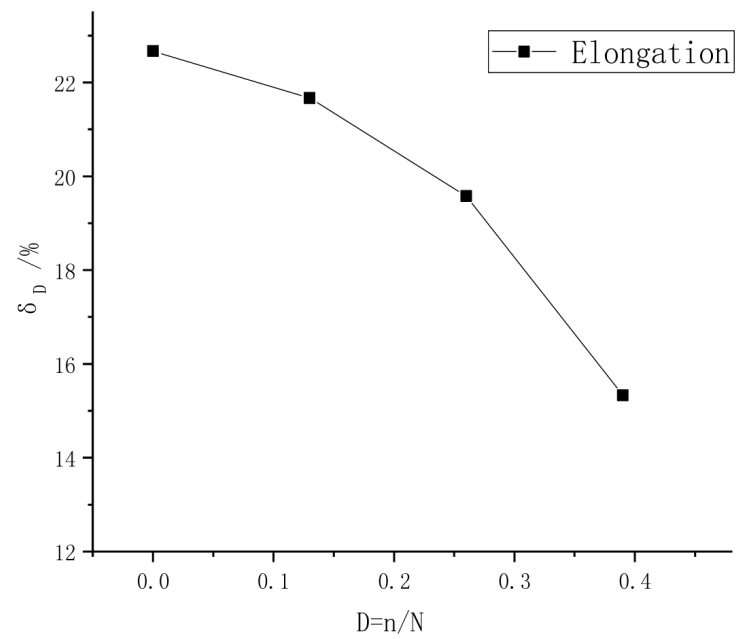

(a)

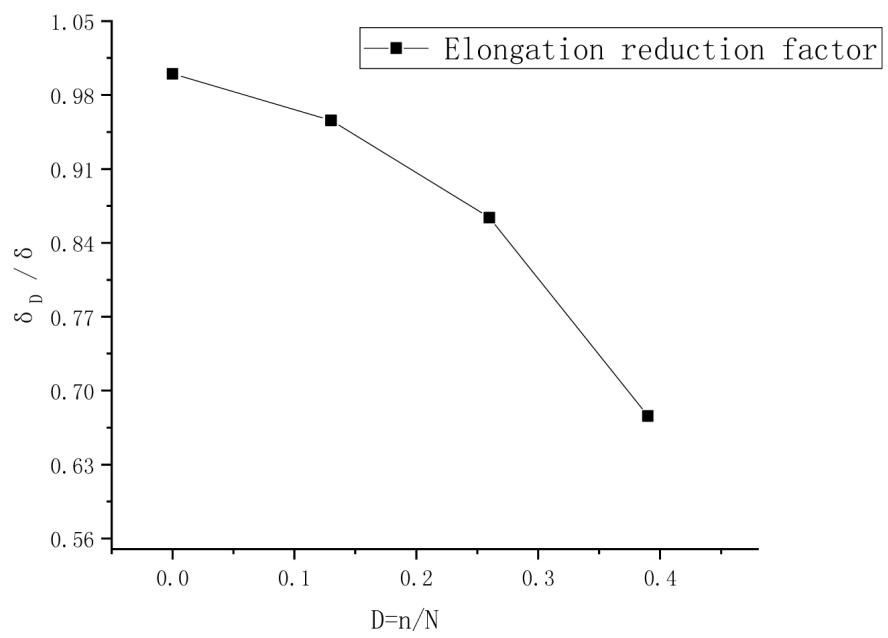

(b)

Figure 7. Comparison of Elongation of Q690 high-strength steel. (a) Elongation of Q690 high-strength steel; (b) Elongation reduction factor of Q690 high-strength steel.

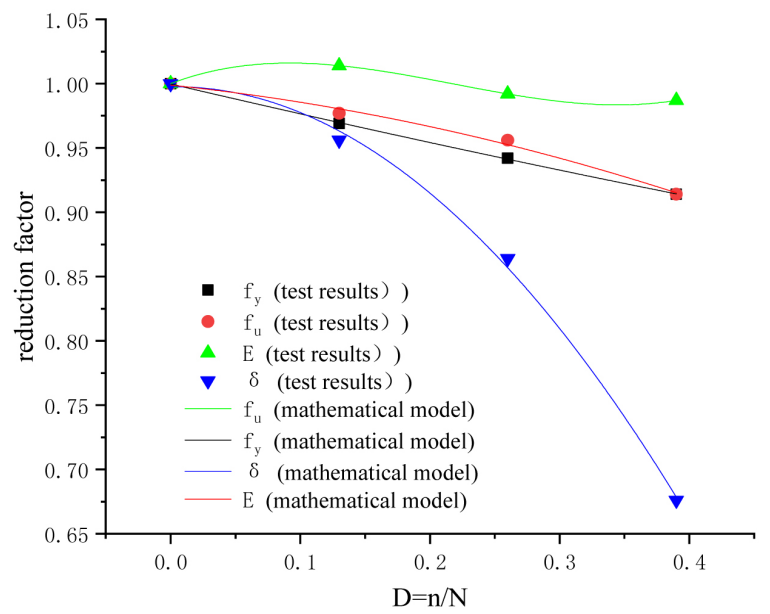

Figure 8. Comparison of mechanical parameters test results and mathematical models of Q690 steel after fatigue damage. 


$$
\begin{aligned}
& \frac{f_{y, D}}{f_{y}}=0.044 D^{2}-0.237 D+1.0 \quad\left(R^{2}=0.99969\right) \\
& \frac{f_{u, D}}{f_{u}}=-0.281 D^{2}-0.105 D+0.999 \quad\left(R^{2}=0.9934\right) \\
& \frac{E_{D}}{E}=4.021 D^{3}-2.633 D^{2}+0.382 D+1 \quad\left(R^{2}=1\right) \\
& \frac{\delta_{D}}{\delta}=-2.13 D^{2}+0.012 D+0.998 \quad\left(R^{2}=0.99814\right)
\end{aligned}
$$

\section{Conclusions}

In this paper, through experiments and theoretical analysis, the change law of fatigue properties of Q690 steel after fatigue damage is deeply studied. The main conclusions are as follows:

1) After the fatigue damage of Q690 high-strength steel, micro-cracks are generated inside the material, which reduces the plasticity of the material, and its stress-strain curve has no obvious yield plateau.

2) The yield strength and ultimate strength of Q690 high-strength steel after fatigue damage decreased with the increase of fatigue damage, but the decrease range was small. When the fatigue damage value is $0.13,0.26$ and 0.39 , the yield strength is reduced by $3.08 \%, 5.83 \%$ and $8.56 \%$ respectively compared with the non-damaged steel. The ultimate strength is reduced by $2.27 \%, 4.37 \%$ and $8.60 \%$ respectively compared with the non-damaged steel; the elastic modulus of Q690 high-strength steel is less affected by fatigue damage. When the fatigue damage value is $0.13,0.26$ and 0.39 , the elastic modulus does not change by more than $2 \%$ compared with the non-damaged steel, and the change has no obvious regularity, and the variation has no obvious regularity.

3) Fatigue damage makes Q690 high-strength steel appear fatigue cycle softening, elongation decreases with the increase of fatigue damage, and the greater the fatigue damage value, the more obvious the decreasing trend. When the fatigue damage value is $0.13,0.26$ and 0.39 , the elongation is reduced by $4.41 \%$, $13.63 \%$ and $32.38 \%$ respectively compared with the non-damaged steel.

4) The analysis of yield strength, ultimate strength, elastic modulus and elongation of Q690 high-strength steel after fatigue damage can refer to the mathematical expressions in the text for corresponding calculations. The degree is poor, and a large number of experimental studies are still needed to be done in the follow-up.

\section{Conflicts of Interest}

The author declares no conflicts of interest regarding the publication of this paper.

\section{References}

[1] Guo, H., Mao, K., Wan, J., Hao, J., Li, S. and Wang, Z. (2019) Research Progress on 
Fatigue Properties of High-Strength Steel. Journal of Building Structures, 40, 17-28.

[2] Haaijer, G. (1961) Economy of High Strength Steel Structural Members. Journal of the Structural Division, 87, 1-23. https://doi.org/10.1061/JSDEAG.0000719

[3] Li, G., Wang, Y., Chen, S. and Sun, F. (2013) Research Status of High-Strength Structural Steel and Its Application in Seismic Fortified Areas. Journal of Building Structures, 34, 1-13.

[4] Feng, D. (2019) Research on Fatigue Properties of Q345B Steel after Neutral Salt Spray Corrosion. China University of Mining and Technology, Xuzhou.

[5] Lei, H., Fu, Q. and Liu, X. (2010) 30-Year Progress in Fatigue Research of Steel Structures in China. Journal of Building Structures, 31, 84-91.

[6] Zhang, C., Zhu, H. and Wang, R. (2021) Experimental Study on Mechanical Properties of Q690 High-Strength Steel after Fatigue Damage. Journal of Building Structures, 42, 177-184.

[7] Tan, Q., Deng, Y., Wang, F. and Shan, C. (2017) Effects of Fatigue Cycle on the Microstructure and Mechanical Properties of A7005 Aluminum Alloy Profiles. Hot Working Technology, 46, 47-51.

[8] Wang, X., Zhang, W., Ni, J., Zhang, T., Gong, J. and Abdel Wahab, M. (2018) Quantitative Description between Pre-Fatigue Damage and Residual Tensile Properties of P92 Steel. Materials Science \& Engineering A, 744, 415-425.

https://doi.org/10.1016/j.msea.2018.12.029

[9] Wu, Z. (2001) Study on the Mechanism of Fatigue Damage and Mechanical Properties Degradation of Metal Materials. Mechanical Strength, No. 2, 216-218.

[10] Wang, W., Zhang, Y. and Li, X. (2021) Experimental Study on Mechanical Properties of High-Strength Q960 Steel after High Temperature. Journal of Building Materials, 114, Article ID: 103010. https://doi.org/10.1016/j.firesaf.2020.103010

[11] Shi, G. and Zhang, J. (2014) Experimental Study on Fatigue Properties of High-Strength Structural Steel Q460D. Industrial Architecture, 44, 6-10.

[12] GB/T3075-2008: Axial Force Control Method for Fatigue Test of Metal Materials (2008). China Standard Press, Beijing.

[13] GBT228.1-2010: Tensile Test Method for Metallic Materials at Room Temperature (2011). China Standard Press, Beijing.

[14] Gao, Z. and Xiong, J. (1986) Fatigue Applied Statistics. National Defense Industry Press, Beijing, 382-392.

[15] Zhang, C. (2012) Research on Fatigue Performance of Transmission Tower and Line System under the Coupling Action of Corrosive Environment and Wind-Induced Fatigue. Chongqing University, Chongqing.

[16] Mroziński, S., Egner, H. and Piotrowski, M. (2019) Effects of Fatigue Testing on Low-Cycle Properties of P91 Steel. International Journal of Fatigue, 120, 65-72. https://doi.org/10.1016/j.ijfatigue.2018.11.001 